\title{
Fracture Analysis of CNG High Pressure Container using Fractography and Measurement of Property
}

\author{
Eui-Soo Kim ${ }^{1, a}$ \\ ${ }^{1}$ Dept. of Safety Engineering, Korea National University of Transportation, Chungju-si, Chungbuk 27469, Korea
}

\begin{abstract}
Bursting accidents of pressure containers due to design and manufacturing defects are frequently occurring. Due to high-pressure gas or harmful substances, when this vessel is fractured, it can lead to catastrophic disasters. Especially, in the event of bursting accident of composite pressure vessel for CNG bus, many unspecified people can be damaged. Most of the accidents were caused by problems in the manufacturing process. The manufacturing process for TYPE2 pressure vessel is very complicated such as three drawing processes, two ironing processes and one spinning process. In the middle of process, various heat treatments are performed for imparting toughness and removing residual stresses. It should cause a serious problem such as bursting and fragmentation of the pressure container due to defects of this process. In this research, the fracture cause of CNG vessel is evaluated through fractography and measuring material property using IIT and analysis of chemical composition.
\end{abstract}

\section{Introduction}

Bursting accidents of pressure vessels due to design and manufacturing defects are frequently occurring. Unlike other structures, Most of the high-pressure vessels contain high-pressure gas or toxic and harmful substances. When this vessel is bursting, it can lead to catastrophic disasters.[1] Especially, in the event of bursting accident of composite pressure vessel for CNG bus, many unspecified people can be damaged. Therefore, the safety and stability of CNG pressure vessel is very important. TYPE 2 container mainly used in Korea is reinforced with a circumferential direction by hoop wrapping glass fiber on steel liner. The CNG composite pressure vessel was made of a metal liner with epoxy-glass fiber composite material. Most of the fracture accidents in TYPE 2 were caused by problems in the manufacturing process. Especially, defect of the heat treatment process may cause a serious problem such as bursting and fragmentation of the pressure vessel. In this research, the investigation of explosive accident resulting from fracture of the pressure vessel is conducted by analyzing failure mechanism and any of the defect of the design and manufacturing process through fractography and measurement of mechanical and chemical property and comparison of stress state using computational numerical analysis in term of forensic engineering and suggest how to improve stability and reliability of CNG pressure vessel .[2][3]

\section{Background of explosive accident}

This accident was caused by bursting of CNG container loaded in the vehicle while charging the CNG bus at the CNG gas station as shown in Figure 1. The lower dome of the bursting pressure vessel is separated from the main body and this caused damage to the surrounding area by penetrating the upper part of the bus that was parked nearby. The accident CNG bus was equipped with a total of eight metal liners which is charged through connection pipes and the explosive liner is the sixth liner from the front of the bus.[4] The charger is equipped with three safety devices: mechanical safety valve, pressure switch, and pressure controller. The charging status of the charger is monitored and this record is stored automatically. Looking at the charging system, At the time of the accident, the gas pressure to the vessel is about $150 \sim 180$ bar and malfunctions \& specific defects are not observed. Therefore, possibility of accident due to charging overpressure and surrounding environment is very low. After all, the root cause of the explosive accident can be found in the problem of container itself such as defects of the design and manufacturing. To identify the exact causes of the CNG vessel failure, it is necessary to collect and investigate the fracture fragments of the vessel, which include composite parts, clamps. 


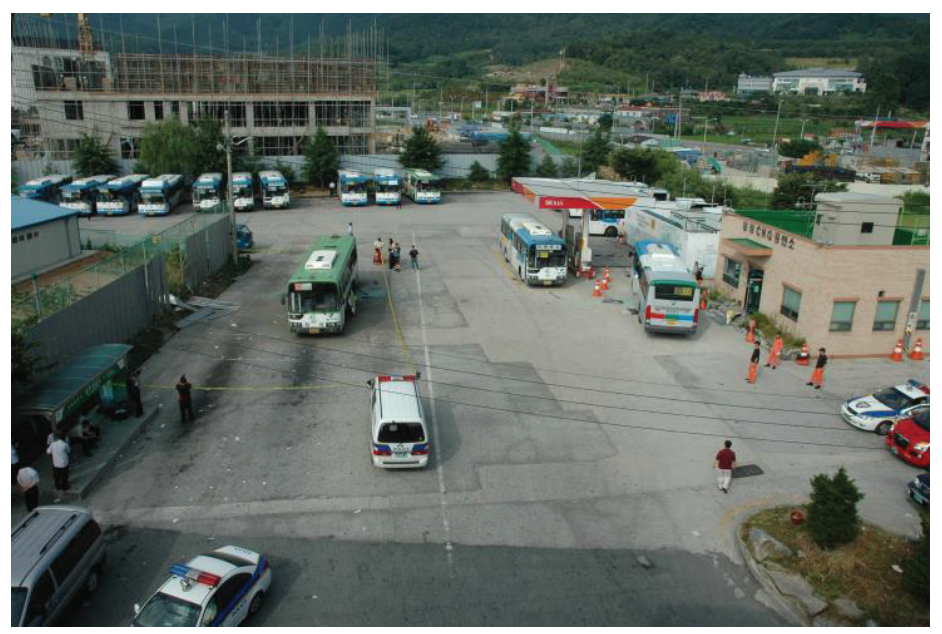

Figure 1. Scene of explo sive accident of CNG buses

\section{Fracture analysis of CNG container}

\subsection{Manufacture and charging process}

When CNG is stored in the vessel by using a 4-stage reciprocating compressor, the gas inlet pressure of 3.5 4.5 bar can be increased by at least 200 bar. Compressed gas from the vessel is supplied to the inner container of the engine after reducing the high pressure of gas to a working pressure level through a pressure reducing valve. CNG composite pressure vessel for the purpose of containing high pressure gas have complicated manufacturing process. The pressure vessel of CNG vehicles is divided into four types which is dependent on the type of materials and composite materials used. TYPE 2 mainly used in CNG buses of Korea is reinforced with a circumferential direction by hoop wrapping glass fiber on steel liner. The TYPE 2 pressure vessel was made of a metal liner (34CrMo4 material) with epoxy-glass fiber composite material.[5] The composite material was wound around the cylinder part of the metal liner, forming a composite overwrapped pressure vessel. The manufacturing process of fractured metal liner consists of three drawing processes and two ironing processes and one spinning process for finalizing the dome part as show in Figure 2. In the middle of process, various heat treatments such as quenching, tempering, and annealing are performed for imparting toughness and removing residual stresses. The heat treatment process is the key process in the manufacturing of metal materials. Therefore, if there is a defect in the heat treatment process, it may cause a serious problem such as bursting and fragmentation of the pressure vessel.

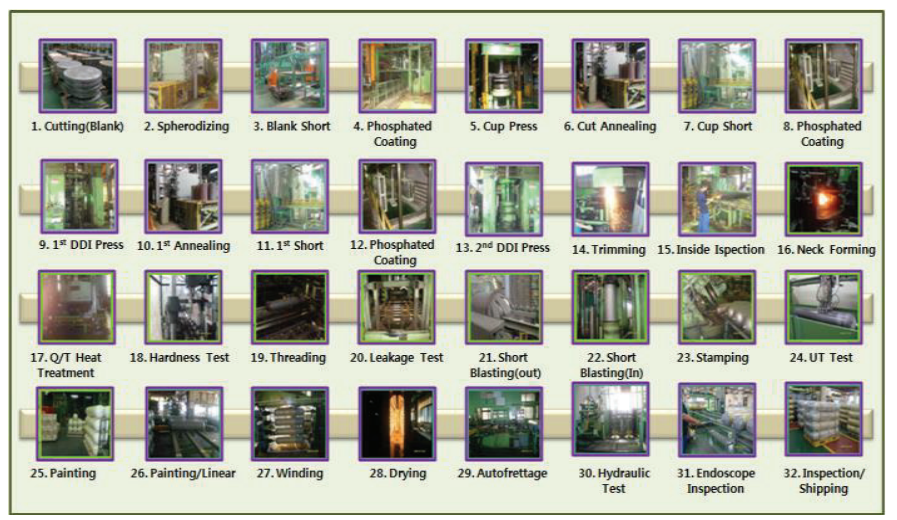

Figure 2. Manufacture process of $\mathrm{CNG}$ container

\subsection{Visual inspection}

The lower dome of the liner is fractured and separated from the body as shown in Figure 3 . The traces of damage before an accident are not observed in the laminate of the composite material and the composite part was burst dependently by fracture of inner liner. In the result of observation after removing composite material, fracture of the liner was progressing along the axial direction. Also, severe corrosion patterns are observed on the surface around the fracture section and marks of the combustion reaction such as soot is not identified inside and outside the liner. A chevron mark which can determine the point of the crack initiation and the direction of the crack propagation in the axial fracture section of the lower dome and the body is observed. In the result of watching this mark, the shape of serration was observed in the section of the circumferential direction at a point $4 \mathrm{~cm}$ from the point where the lower dome of the liner meets the body. It is recognized that the crack propagates from the division 
where the shape of serration is observed to the axial direction. Looking at the fracture section of crack initiation, The corrosion layer is locally observed and the forms of brittle and ductile fracture are simultaneously identified.

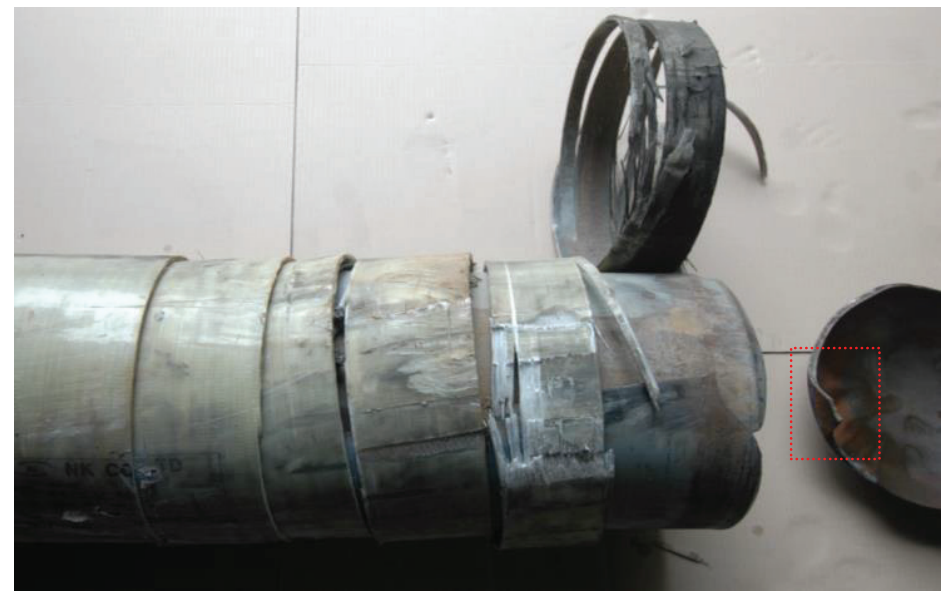

Figure 3. Fracture and corrosion pattern of $\mathrm{CNG}$ container

\subsection{Fractography using SEM and OM}

The crack point on the crack initial surface was carefully observed by scanning electron microscopy (SEM) as shown in Figure 4., Figure 5. In case of TYPE 2 pressure container, metallic liner is manufactured of one circular blank by drawing and ironing continuous process. Depending on the process characteristics, vertical and parallel directions in the extrusion direction, the mechanical and structural properties in the container are different. Therefore, in order to examination mechanical properties and micro-structure of crack point, Test is examined according to the extrusion vertical direction (one direction) and parallel direction (second direction). As a result of the inclusion inspection, special point was not identified in all directions as shown in Figure 6. Martensite structure was observed as a result of micro-structure examination. However, it shows fine martensite structure in the cross section perpendicular to the extrusion direction, but coarse martensite was identified in the cross section parallel to the extrusion direction as shown in Figure 7. Martensite is observed in the entire region of the vessel which must have the quenching and tempering process, and it is judged that there is a defect in the heat treatment of the tempering skip. It can be seen that it is very brittle and the fragmented because the toughness is not given. As a result of FE-SEM observation, we know that the precipitation was seen much more in vertical cross section than the parallel cross section of the extrusion direction.

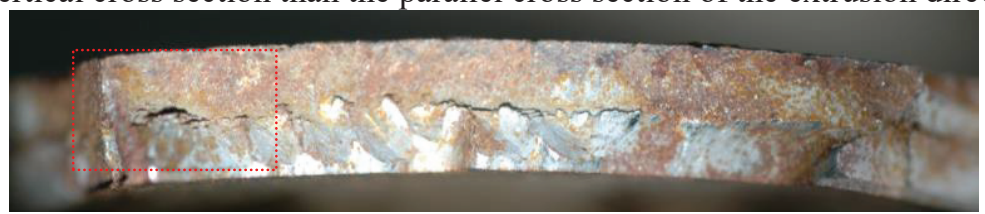

Figure 4. Microscope mage of crack initial area

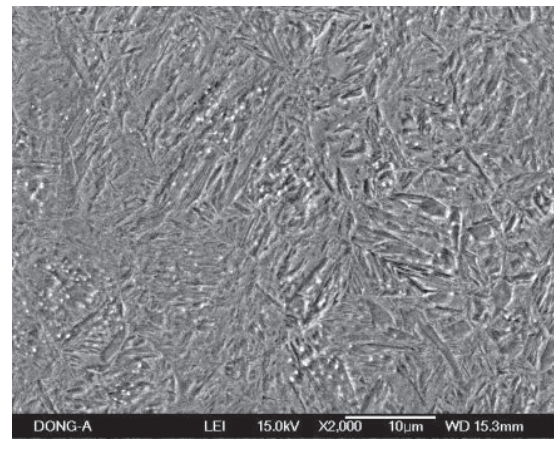

(a)Vertical to extruding direction

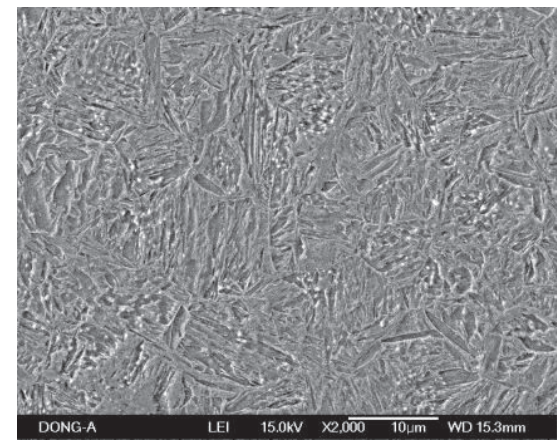

(b) Horizontal to extruding direction

Figure 5. SEM Images of crack initial point (2000x) 


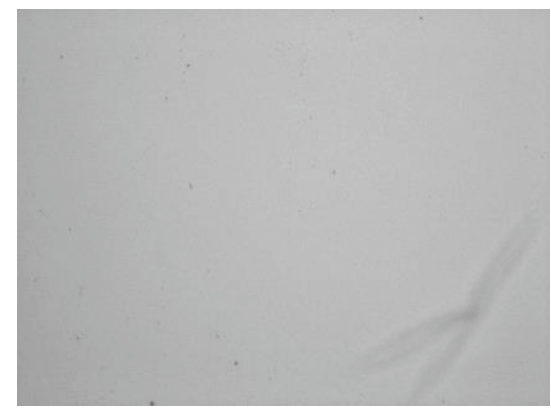

(a)Vertical to extruding direction

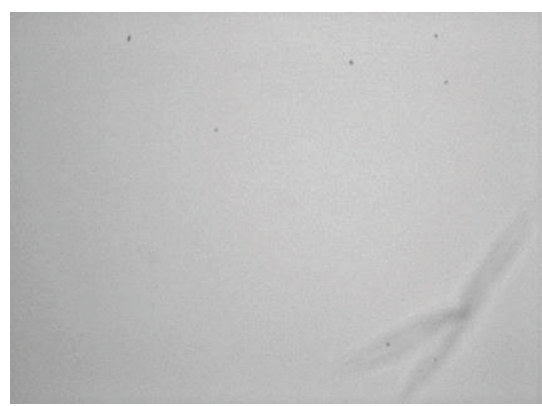

(b) Horizontal to extruding direction

Figure 6. OM Images for inclusion(100x)

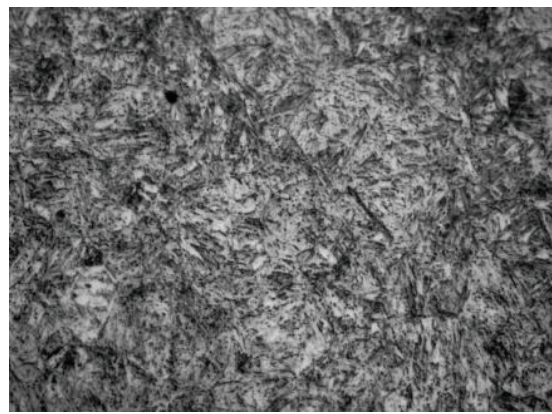

(a)Vertical to extruding direction

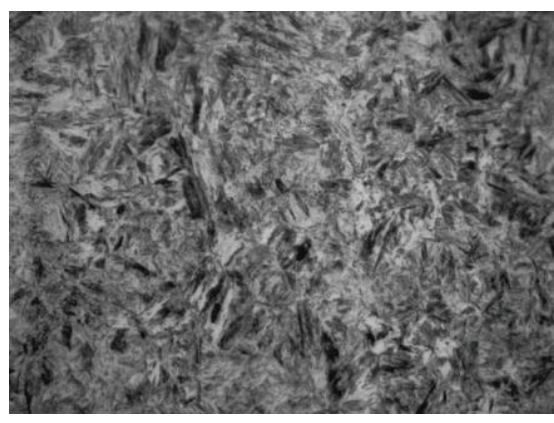

(b) Horizontal to extruding direction

Figure 7. OM Images for martensite (1000x)

\subsection{Measurement of property}

In order to ascertain the singularity of the chemical composition of the liner part of the fracture initiation point, as a result of component analysis according to photoelectric photometric emission spectroscopic analysis method of iron and steel (KSD 1652: 2007) as shown in Table 1.[6] The value is satisfying a given design condition. In order to evaluate mechanical properties, specimens were collected for each site along each crack propagation line. Mechanical properties were evaluated by IIT(Instrumented Indentation). Based on the evaluation process of ISO TR29381and KS B 0950:2002, IIT is designed to determine the mechanical properties by putting an indentation in the specimen's surface.[7][8] This method is known to be a powerful tool to probe the mechanical response of various engineering materials when irregularly shaped fragments of mechanical parts need to be analyzed. The results are shown in Table 2. comparing with yield strength ( $840 \mathrm{MPa})$ and longitude value $(270$ to $321 \mathrm{HV}$ ) of the design condition. All of the value far exceeded the design condition. Here, $\mathrm{n}$ is the work hardening index, YS is the yield strength, UTS is the breaking strength, E is the elastic modulus, HV is the Vickers hardness, and HR - A is the Rockwell hardness. As for material analysis, the liner satisfies the chemical composition ratio, hardness value does not satisfy the design range. Generally, the variation in the hardness value results from inappropriate heat treatment such as quenching and tempering in the manufacturing process. In the case of the container of this accident, the value of hardness far exceeds the design condition by inappropriate heat. If the value of hardness increases, brittleness becomes high and it induces a condition which is extremely vulnerable to hydrogen brittleness and fatigue failure.

Table 1. Result of chemical composition

\begin{tabular}{|c|c|c|c|c|c|c|c|c|}
\hline Copo. & $\mathrm{C}$ & $\mathrm{Si}$ & $\mathrm{Mn}$ & $\mathrm{P}$ & $\mathrm{S}$ & $\mathrm{Cr}$ & $\mathrm{Ni}$ & $\mathrm{Mo}$ \\
\hline Standard & $0.32-0.37$ & $0.15-0.35$ & $0.60-0.90$ & $\sim 0.015$ & $\sim 0.010$ & $0.90-1.15$ & $\sim 0.25$ & $0.20-0.25$ \\
\hline Measure & 0.345 & 0.222 & 0.73 & 0.006 & 0.003 & 0.985 & 0.246 & 0.188 \\
\hline
\end{tabular}

Table 2. Result of mechanical property

\begin{tabular}{|c|c|c|c|c|c|c|}
\hline E. V & $\mathrm{n}$ & $\mathrm{YS}(\mathrm{MPa})$ & UTS(MPa) & $\mathrm{E}(\mathrm{Gpa})$ & HV & HR-A \\
\hline Mean of val. & 0.201 & 1043.2 & 1466.3 & 208.3 & 490.1 & 74.9 \\
\hline
\end{tabular}




\section{Conclusions and recommendations}

In this research, in order to investigate the cause of the explosion accident of the CNG pressure vessel, the fracture evaluation of the container accomplish using fractography and measurement method of mechanical engineering. As a result of analysis, A local corrosion layer and pattern of cleavage fracture is identified. In term of the material analysis, although the liner is satisfied with the chemical composition ratio, the hardness value of the mechanical properties does not satisfy the design value. Because brittleness is high due to improper heat treatment, that increase a possibility of causing cleavage fracture with little plastic deformation. We recommend how to improve the safety and reliability of pressure vessels. Firstly, we have to prevent non-experts from making an error by automation everything from design to inspection. Secondly, We suggest to replace the TYPE 2 pressure vessel with TYPE 3 pressure vessel which is more effective than the TYPE 2 in term of LBB(Leaked Before Break) effect. Thirdly, We ask for increasing supply of the ground bus which mount pressure vessel to the upper of bus in order to release immediately inner gas without any residue when CNG leaked.

\section{Acknowledgement}

This research was supported by Basic Science Research Program through the National Research Foundation of Korea(NRF) funded by the Ministry of Education(2017R1D1A1B03028163)

\section{References}

1. E.S. Kim, N.K. Park, Y.H. Kim, KOSOS, A forensic engineering study on bursting accident of composite pressure vessel in CNG bus, 23, 15-21 (2008)

2. D.H. Michael, B.E. Dale, R.S. Anand, Fractography in Failure Analysis of Polymers, Fractography as a Failure Analysis Tool, 6-22 (2015)

3. S.M. Goushegir, J.F. Dos Santos, S.T. Amancio-Filho, Composites Part A: Applied Science and Manufacturing, Failure and fracture micro-mechanisms in metal-composite single lap joints produced by welding-based joining techniques, 81, 121-128 (2016)

4. S. Chamberlain, M. Modarres, Risk Analysis, Compressed Natural Gas Bus Safety: A Quantitative Risk Assessment, 25 (2005)

5. E.S. Kim, J.H. Kim, Y.S. Park, C.J. Choi, KSPE, Development of an automated design system of CNG composite vessel using steel liner manufactured by D.D.I process, 20, 205-213 (2003)

6. Korean Standards, Iron and steel-Method for spark discharge atomic emission spectrometric analysis, KS D 1652:2016, (2016)

7. K.H. Kim, Y. Choi, S.H. Kim, J.S. Lee, D.I. Kwon, Spring conference of KSME, Application of Instrumented Indentation Technique for Nondestructive/Mechanical Properties Measurement of In-service Components and Materials, 336-343 (2005)

8. A. Sina, C. Xi, M.S. Andrea, G. Marco, International Journal of Mechanical Sciences, Investigation of the mechanical behaviour of lithium-ion batteries by an indentation technique, 105, 1-10 (2016) 